\title{
Editorial
}

\section{Saudades... ou Como Viver o Mundo da Pandemia}

Fernando Atique, Lidia Quiéto Viana, Marcio Cotrim e Rachel Coutinho Marques da Silva

$\mathbf{O}$ número 9 da revista Thésis é revestido de grande simbolismo. Vem a público em um momento de fortes impactos na vida cotidiana de todo o mundo, e marca, também, uma profunda alteração da ordem espacial - doméstica/privada e urbana/pública -, cujos impactos imediatos estamos sentindo, mas sem ainda termos ferramentas suficientes para o dimensionamento dos vindouros.

A decretação da pandemia originada pelo COVID-19, em março de 2020, impôs rotinas novas que alteraram radicalmente a forma como conduzimos nossas vidas. $\mathrm{O}$ aspecto profissional se fundiu de maneira potente e inequívoca com o pessoal, e as casas se transformaram em territórios híbridos, em que as (in)seguranças exteriores se manifestaram diuturnamente. Sem conseguirmos prever a duração de tal quarentena, fomos experimentando semana a semana as novidades - prazerosas e dolorosas - de reuniões, aulas, bancas, cursos, lives, orientações, exposições, debates e também de edição de uma revista. Os procedimentos digitais há anos fazem parte da rotina universitária, mas o impedimento de ações mais descontraídas e presenciais, produziu uma aceleração de demandas que nos impôs uma reflexão: a fragilidade dos limites corporais frente à webesfera. Talvez, muitos de nós, tenhamos sentido pela primeira vez, e com enorme incidência, a ação da compressão tempo-espacial em 2020.

As sensações de falta, perda, ausência e de anseio pelo não visto permearam nossas existências. Estas palavras estão todas embutidas em outra, típica da língua portuguesa: saudade. Não demorou a sentirmos necessidade de estarmos em salas de aulas físicas, em sessões de congressos, em reuniões departamentais, em livrarias, em espaços públicos. Juntos, em corpos e mentes, e não apenas em imagens. 
Saudade também marcou nossos espíritos conforme nos deparamos com perdas de colegas notáveis que partiram ao longo do ano, quer por COVID-19, ou por doenças oportunistas que foram agravadas pelo confinamento e pelo isolamento. Muitas razões para luto e para luta, então, se apresentaram a nós.

Entretanto, permeados por responsabilidades coletivas, nossa vida profissional seguiu. Com a costumeira criatividade de nosso campo profissional, seguimos com afinco e ímpeto propositivo. O número 9 da Thésis, desta maneira, traz consigo este compromisso com a ética e com a memória dos que se foram e daquilo que está no âmago da própria ANPARQ: ser uma entidade múltipla e de representatividade nacional.

A revista, imbuída dos valores da associação à qual se vincula, retoma sua publicação regular, com alguns ajustes. O primeiro diz respeito à plataforma digital de submissão, edição e divulgação. O sistema Open Journal System - OJS - que já estava vinculado à revista, foi atualizado, completamente direcionado ao pleno e correto funcionamento da Thésis, garantindo lisura aos autores, e celeridade no recebimento e tratamento das submissões aos editores, intentando assim, evitar rupturas e perdas das mais diversas ordens. O segundo aspecto a ser pontuado diz respeito ao redesenho da marca da revista. Refletindo este novo ciclo, a marca foi atualizada, e como forma de saudar a expectativa por novos e melhores horizontes, traz cor à sua aparência. Como terceiro ponto, está a possibilidade de submissão de resenhas por interessados, de maneira a garantir, para além do compromisso institucional da ANPARQ na divulgação dos prêmios de nossa área, também uma atualização bibliográfica nos temas que são caros aos arquitetos e urbanistas. Destacamos ainda a nova equipe editorial, incumbida de levar adiante a publicação de quatro números no biênio 2020-2021. Os novos editores são os arquitetos e urbanistas Fernando Atique, docente na Universidade Federal de São Paulo; Lídia Quiéto Viana, docente da Universidade Federal da Bahia; Marcio Cotrim, também da Universidade Federal da Bahia, e Rachel Coutinho Marques da Silva, docente aposentada da Universidade Federal do Rio de Janeiro, e professora do Programa de Pós-Graduação em Arquitetura da Pontifícia Universidade Católica do Rio de Janeiro.

Em termos operacionais, os editores retomaram o funcionamento da revista no que diz respeito a duas dimensões. A primeira alude ao seu quadro consultivo. Não apenas enviamos convites aos Programas afiliados para que indicassem potenciais pareceristas, cum- 
prindo, então, uma das dimensões necessárias para a indexação da Thésis, como demos início, também, à renovação do Conselho Editorial. Esta renovação se dará na proporção de $2 / 3$ dos seus componentes a cada dois anos. Caberá ao conselho a responsabilidade de aprovar o plano editorial elaborado pela comissão editorial.

A segunda dimensão diz respeito à retomada da estrutura da revista. A Thésis passa, a partir deste número, a apresentar as 4 seções: Ensaios, Arquivo, Recensão e Passagens, que figuraram entre os números 1 e 4, e possuíam como estratégia permitir uma demonstração plural das ações inerentes à pesquisa em Arquitetura e Urbanismo. Ensaios recebe artigos originais de pesquisadores, visando a difusão de conhecimento produzidos nos Programas de Pós-Graduação da área. Arquivo é a seção destinada a ampliar a recepção de textos fundamentais de scholars de nossa área, cuja tradução ainda não havia sido feita para o português. Recensão apresenta as resenhas de obras premiadas no Brasil tanto nos certames da própria ANPARQ, quanto no Prêmio Capes de Teses, e, como dito, a partir deste número, a disseminar, também, a opinião de colegas investigadores sobre obras consideradas importantes para a atualização bibliográfica de nossa área. E, finalmente, a seção Passagens mostra as interpretações gráficas de colegas sobre a temática da seção Arquivo, auxiliando na compreensão dos temas e de sua circulação.

Neste número, a seção Ensaios traz 4 artigos. Abre a sessão, Daniel Juracy Mellado Paz, professor da Faculdade de Arquitetura da UFBA com "Dia de Festa no Mar: Maritimidade, hierofanias, heortologia urbana na Salvador oitocentista" que aborda a importância cotidiana, econômica e espiritual do mar para a cidade de Salvador, a relação entre seus festejos relacionados e o processo de urbanização da cidade. Em sequência, João Masao Kamita, Professor do PPGau e do PPG em História Social da Cultura da PUC-Rio, com "Sobre a Praça das Artes" que discorre sobre o caráter contemporâneo no partido, implantação e imagem da Praça das Artes, na cidade de São Paulo, resultado do aspecto fragmentário de sua composição e do contexto urbano imediato. Temos ainda, Flávia Brito do Nascimento, doutora pela FAU USP, com "A construção da ideia de patrimônio moderno no Brasil: valorações e práticas dos anos 1940 aos 2000", que discute as atribuições de valor patrimonial quanto à produção moderna, interpondo documentos para o tombamento formulados por órgãos associados para certos edifícios à historiografia, aos crivos teóricos e aos discursos. Por fim, 
Manuela Catafesta e Fábio Bortoli, ambos professores no curso de arquitetura da UniRitter, com "O Edifício Formac pelas lentes de João Alberto Fonseca da Silva" que nos apresenta parte da história da fotografia do Rio Grande do Sul, e a especificidade da sua prática a partir da fotomontagem com vistas a retratar e discutir a inserção urbana de edifícios de grande altura e o processo de verticalização da cidade.

Arquivo traz a tradução do texto "A dignidade do átimo. As formas do tempo: Veneza e a Modernidade", escrito pelo intelectual italiano Manfredo Tafuri (19351994), em 1993, feita pelo professor Rafael Urano de Carvalho Frajndlich, docente da Universidade Estadual de Campinas, na Faculdade de Engenharia Civil, Arquitetura e Urbanismo. Tafuri é nome incontornável nos estudos de Teoria e História da Arquitetura e do Urbanismo. Com clara e vigorosa produção de filiação marxista, Tafuri, entrelaçado ao IUAV, o mítico Istituto Universitario di Architettura di Venezia, nos legou uma série de pesquisas inovadoras, corporificadas em ensaios, livros, anais de conferências, aulas e capítulos em coletâneas. Nos anos 1980, Tafuri, após incursões sobre as cidades russas e estadunidenses, passou a se dedicar a investigações sobre o Renascimento na Península Itálica, buscando personagens e produtos longe do epicentro florentino e romano. Grande parte do legado de Tafuri ainda não foi traduzido para o português, e esta conferência que vem a público na Thésis, ajuda a reinseri-lo no ambiente brasileiro pelas mãos de um dos mais jovens, e não menos competentes estudiosos de sua obra, o doutor em História e Fundamentos da Arquitetura e do Urbanismo, Rafael Urano Frindlich. Penúltima conferência proferida por Tafuri, antes de sua morte, a conferência trata das formas do tempo, e mostra a imensa erudição e criatividade tafuriana ao relacionar a cidade contemporânea como cenário do conflito entre diferentes noções de temporalidade.

Recensão (re-)publica a resenha ainda inédita em português do livro Lux Pulchritudinis: sobre beleza e ornamento em Leon Battista Alberti, escrito pela professora do Departamento de História da Arquitetura e Estética do Projeto da FAU-USP, Andrea Loewen. Analisado pelo professor Rodrigo Bastos, da Faculdade de Arquitetura e Urbanismo da UFSC, o livro mostra uma pesquisa original sobre o arquiteto Leon Batista Alberti, que fomenta uma retomada de estudos sobre arquitetura do renascimento de maneira profunda.

Recensão traz, ainda, a resenha produzida especialmente para Thésis pela professora Clarissa Freitas, da 
Faculdade de Arquitetura e Urbanismo da Universidade Federal do Ceará, sobre uma das duas teses que recebeu Menção Honrosa, em 2019, no Prêmio Capes de Teses. Analisando o trabalho de Flavia Neves Maia, intitulado "Urbanismo Smart e a política da visibilidade digital: mapeando informalidade na cidade do Rio de Janeiro (2008-2016)", defendido no PROURB da UFRJ, em 2018, sob orientação da professora Rachel Coutinho M. da Silva, Freitas descortina a riqueza da investigação da jovem doutora sobre as noções de urbanismo interligente (SU) e visibilidade digital, na qual discute o processo de mapeamento das favelas no Rio de Janeiro, a disputa informacional que smartphones e empresas de tecnologia tem fomentado, e o suposto potencial que vincula os mapeamentos digitais à processos de inclusão urbana.

A seção Passagens é assinada pelo professor Matheus Rosada, da Escola de Arquitetura da UFMG, que analisando a conferência de Manfredo Tafuri, aqui publicada, produz um ensaio criativo sobre as temporalidades do pensador italiano e as formas de enxergar o tempo. Amarradas por um fio condutor claro, as reflexões e indagações de Rosada são tecidas através de um paralelo entre as ideias de Tafuri e o caráter genuíno e particular das nossas cidades ditas coloniais. Ao percorrer essa construção, permeada de trabalhos gráficos do autor, é ainda colocada a complexa relação entre o patrimônio e o tempo, que reforça uma reflexão necessária ao campo e sua amplitude.

A capa da revista foi montada a partir de uma colagem, elaborada pela professora Lídia Quiéto, da Faculdade de Arquitetura da UFBA, que teve partida e inspiração na conferência de Manfredo Tafuri, já mencionada. Parte, portanto, da sua interpretação dos diferentes tempos: o tempo do átimo, que seria a "flecha do tempo"; o tempo do consumo, descartável e o tempo quase imóvel, intocável de lugares mais isolados e mais dissociados dos processos técnicos do tempo. Esses tempos são tratados como camadas da colagem, ressaltadas por cores, remetendo também a cidade contemporânea, resultado de sobreposições dessas distintas camadas de tempo e de seu registro material. Por fim, soma-se ainda a camada desse tempo imediato da pandemia, da simbologia do nevoeiro e de um vírus que permeia todos os ambientes e nos coloca nessa realidade em que tudo nos atravessa e se mescla em um só tempo. 
1 Pessoa, Fernando. Natal... Na província neva. In O Notícias Ilustrado, no 29. Lisboa: 30-12-1928.
A ideia referida neste editorial da supressão tempo-espacial, revela-se no número 9 da Thésis, assim, em muitas páginas. Saudade é um sentimento recorrente, e muito atual. Fernando Pessoa, em seus versos publicados no Natal de 1928, evocou algo que pode nos explicar ao fim deste ano pandêmico de 2020:

Coração oposto ao mundo,

Como a família é verdade!

Meu pensamento é profundo,

Estou só e sonho saudade.

E como é branca de graça

A paisagem que não sei,

Vista de trás da vidraça

Do lar que nunca terei! ${ }^{1}$

Com os versos do poeta português, listamos, a seguir, nossa homenagem a diversos colegas que nos deixaram.

\section{Homenagem Post-Mortem}

\author{
Alda Rabello Cunha \\ Aluísio Costa Filho \\ Ayrton Lolô Cornelsen \\ Benedito Lima de Toledo \\ Carolina Bueno \\ Dácio Ottoni \\ Esterzilda Berenstein de Azevedo \\ Fernando Alvarez Prozorovich \\ Gian Carlo Gasperini \\ Hélia Nacif Xavier \\ Joaquim Caetano de Lima Filho \\ Jorge Alberto Maldonado Y Vaz \\ Juan Luis Mascaró \\ Julio Abe Wakahara \\ Júlio Artigas \\ Lúcio Kowarick \\ Marina Kohler Harkot \\ Martt Aris \\ Michael Sorkin \\ Nelci Tinem \\ Severiano Mario Porto \\ Vittorio Gregotti \\ Wilson Cano
}

